\title{
Construct Validity of a Two-Factor Model of Psychopathy
}

\author{
Heather Douglas, Miles Bore, Don Munro \\ School of Psychology, University of Newcastle, Newcastle, Australia \\ Email: Heather.Douglas@newcastle.edu.au \\ Received November $9^{\text {th }}, 2011$; revised December $10^{\text {th }}, 2011$; accepted December $31^{\text {st }}, 2011$
}

\begin{abstract}
There is currently limited evidence for the two-factor structure of Psychopathy. The aim was to provide evidence for the construct validity of Primary and Secondary Psychopathy. Batteries including the Five Factor Model, the Hogan Development Survey, and Narcissism, Machiavellianism, Empathy, and Aggression, were administered to 241 undergraduate psychology students. Confirmatory factor analysis indicated that a two component structure fitted the data reasonably well (chi-square $=1.939, \mathrm{CFI}=.799$, RMSEA $=.063$ ). The strongest markers of Primary Psychopathy were Agreeableness, Empathy, and the HDS Bold and HDS Colourful subscales, while the strongest markers of Secondary Psychopathy were Neuroticism, Conscientiousness, and HDS Excitable. It was concluded that preliminary evidence for the two-factor model of Psychopathy had been gained.
\end{abstract}

Keywords: Construct Validity; Levenson Self-Report Psychopathy Scale; Five-Factor Model; Hogan Development Survey

\section{Introduction}

The construct of Psychopathy has been of interest to psychologists for some time (Lee \& Salekin, 2010). On the basis of clinical observation, Cleckley (1955) posited a clinical profile of the psychopathic personality that included as its key features inadequately motivated antisocial behaviour, a lack of remorse or shame, and a general poverty in major affective reactions. High levels of the trait have been associated with violence, criminal recidivism, and antisocial behaviour in both forensic and general populations (Flores-Mendoza, Alvarenga, Herrero, \& Abad, 2008; Freidenfelt \& Klinteberg, 2007; Vitacco, Neumann, \& Jackson, 2005).

The literature on the measurement of Psychopathy indicates disagreement over the construct's structure, with anywhere from two to eight separate factors proposed (Forth, Brown, Hart, \& Hare, 1996; Lilienfeld \& Andrews, 1996; Vitacco, Neumann, \& Jackson, 2005; Williams, Paulhus, \& Hare, 2007). A twofactor model was proposed by Karpman (1948), which has been empirically demonstrated in the Psychopathy Checklist (PCL-R; Hart \& Hare, 1989; Templeman \& Wong, 1994). The first factor was labelled Primary Psychopathy, which consists of callous, selfish and manipulative personal attitudes. Secondary Psychopathy is characterised by high impulsivity and emotional instability, coupled with a self-defeating lifestyle. Both factors of Psychopathy are negatively related to Agreeableness from the Five Factor Model (Lynam\&Derefinko, 2006) and Empathy (Andrew, Cooke, \& Muncer, 2008; Munro, Bore, \& Powis, 2005; Wastell \& Booth, 2003). They are also positively related to Aggression (Ross, Bye, Wrobel, \& Horton, 2008), Narcissism (Jakobwitz \& Egan, 2006; Paulhus \& Williams, 2002), and diagnoses of Antisocial Personality Disorder (Blackburn \& Coid, 1998).

The Levenson Self-Report Psychopathy Scale (LSRP; Levenson, Kiehl, \& Fitzpatrick, 1995) was designed from items on the PCL-R structured interview to reflect the above-mentioned two-component structure. Exploratory factor analysis on the initial item pool clearly indicated two factors. Subsequent confirmatory factor analyses (CFA) appear to replicate this structure (Brinkley, Schmitt, Smith, \& Newman, 2001; Lynam, Whiteside, \& Jones, 1999). However some issues with the reporting of previous CFA results and the theoretical justification for the model suggest that confirmation of these results would be worthwhile.

An aspect of providing evidence for the two-factor structure of Psychopathy involves the need to establish the differential validity of Primary and Secondary Psychopathy. The focus of research on the LSRP appears to have been on replicating the factor structure rather than examining differential construct validity. Levenson, Kiehl and Fitzpatrick (1995) provided the initial investigation of this issue. They found that Primary Psychopathy was related to harm avoidance and a lack of inhibition, whereas Secondary Psychopathy was related to boredom susceptibility. Lynam, Whiteside and Jones (1999) investigated the relationships of Psychopathy with the Five Factor Model. Primary Psychopathy was found to have a negative correlation with Agreeableness, while Secondary Psychopathy was negatively correlated with Agreeableness and also with Conscientiousness, but positively with Neuroticism. These results suggest that the two factors of Psychopathy should have different correlates.

Psychopathy has also demonstrated relationships with the DSM-IV defined Personality Disorders in forensic populations (Blackburn \& Coid, 1998; Decuyper, De Fruyt, \& Buschman, 2008; Hart \& Hare, 1996; Ross, Bye, Wrobel \& Horton, 2008). However, the research used clinical tools, which are designed to diagnose people with significant deficits in psychological functioning. The Hogan Development Survey (HDS) was designed for organisational contexts, to identify the presence of sub-clinical personality traits reflective of the Axis II disorders. It consists of eleven scales mapping onto the DSM-IV defined Personality Disorders, the names of which can be found in Table 1. Research indicates that Primary Psychopathy is associated with Narcissistic and Histrionic Personality Disorders 
Table 1.

Description of each of the HDS scales (Hogan, 2001).

\begin{tabular}{|c|c|c|}
\hline DSM-IV PDs & HDS Scale & Description \\
\hline Borderline & Excitable & $\begin{array}{l}\text { Moody, hard to please, intense but } \\
\text { short-lived enthusiasm for people, projects, } \\
\text { or things. }\end{array}$ \\
\hline Paranoid & Sceptical & $\begin{array}{l}\text { Cynical, distrustful, and doubting others' } \\
\text { intentions. }\end{array}$ \\
\hline Avoidant & Cautious & $\begin{array}{l}\text { Reluctant to take risks for fear of being } \\
\text { rejected or negatively evaluated. }\end{array}$ \\
\hline Schizoid & Reserved & $\begin{array}{l}\text { Aloof, detached, and uncommunicative, } \\
\text { lacking interest or awareness of the feelings } \\
\text { of others. }\end{array}$ \\
\hline $\begin{array}{l}\text { Passive- } \\
\text { Aggressive }\end{array}$ & Leisurely & $\begin{array}{l}\text { Independent, ignoring people's requests and } \\
\text { becoming irritated or argumentative if they } \\
\text { persist. }\end{array}$ \\
\hline Narcissistic & Bold & $\begin{array}{l}\text { Unusually self-confident, feelings of } \\
\text { grandiosity or entitlement, over-evaluation } \\
\text { of one's capabilities. }\end{array}$ \\
\hline Antisocial & Mischievous & $\begin{array}{l}\text { Risk taking and testing the limits, needing } \\
\text { excitement, manipulative, deceitful, cunning, } \\
\text { and exploitative. }\end{array}$ \\
\hline Histrionic & Colourful & $\begin{array}{l}\text { Expressive, animated, and dramatic, wanting } \\
\text { to be noticed and needing to be the centre of } \\
\text { attention. }\end{array}$ \\
\hline Schizotypal & Imaginative & $\begin{array}{l}\text { Acting and thinking in creative and } \\
\text { sometimes odd or unusual ways. }\end{array}$ \\
\hline $\begin{array}{l}\text { Obsessive- } \\
\text { Compulsive }\end{array}$ & Diligent & $\begin{array}{l}\text { Meticulous, precise, perfectionistic, } \\
\text { inflexible about rules and procedures, critical } \\
\text { of others' performance. }\end{array}$ \\
\hline Dependent & Dutiful & $\begin{array}{l}\text { Eager to please and reliant on others for } \\
\text { support and guidance, reluctant to take } \\
\text { independent action or go against popular } \\
\text { opinion. }\end{array}$ \\
\hline
\end{tabular}

(Hart \& Hare, 1996; Hildebrand \& de Ruiter, 2004), which would correspond to the HDS Bold and Colourful scales respectively. Secondary Psychopathy, on the other hand, has demonstrated relations with Borderline and Paranoid personality traits (Hart \& Hare, 1996), which map onto the Excitable and Sceptical HDS scales respectively. Establishing these relationships in a normal population would provide further evidence for the construct validity of the two-factor model of Psychopathy.

An additional construct of interest to Primary Psychopathy in particular is that of Machiavellianism, which consists of the manipulativeness and the degree to which a person assumes that others are manipulable (Christie \& Geis, 1970). Machiavellianism has most commonly appeared in the literature as a component of the Dark Triad (Paulhus \& Williams, 2002), which consists of Narcissism, Machiavellianism, and Psychopathy. In fact, the results reported in the current study were a part of a larger project examining the construct validity of the Dark Triad (Douglas, Bore, \& Munro, 2012). The uncertainty in the literature regarding the factor structure of Psychopathy warranted the current exploration. Like Narcissism, Machiavellianism was first assumed to be related to both Primary and Secondary Psychopathy (Lee \& Ashton, 2005). However, recent evidence has emerged indicating that Machiavellianism may be more closely related to Primary Psychopathy (Lynam, 2002; Wastell \& Booth, 2003). This finding, if replicated, would provide further evidence for the difference between the two
Psychopathy constructs.

The aim of the current study is to provide evidence for the construct validity of a two-factor model of Psychopathy. As a first step in this process, the component structure of the LSRP was replicated using confirmatory factor-analytic techniques, with a two factor model expected to provide a good fit to the data. The differential correlates of both Primary and Secondary Psychopathy were then examined. It was expected that the two factors of Psychopathy would have different relationships in the nomological network of interest, such that:

1) Both Primary and Secondary Psychopathy are negatively related to Agreeableness and Empathy, as well as positively related to Aggression, Narcissism, and the HDS Mischievous scale, corresponding to Antisocial Personality Disorder Traits.

2) In addition, Primary Psychopathy is associated with the Bold and Colourful HDS scales, corresponding to Narcissistic and Histrionic Personality Disorders; it should also be negatively associated with Machiavellianism.

3) Secondary Psychopathy is also negatively related to Conscientiousness, as well as positively with Neuroticism, Excitable (Borderline) and Sceptical (Paranoid) HDS scales.

\section{Method}

\section{Participants}

Participants were recruited from a first year psychology cohort in 2009 at an Australian University and were awarded course credit for their introductory psychology course. Two hundred and forty-one participants were recruited, 189 of whom were female $(78.4 \%)$. Fourteen participants did not report their gender (5.8\%). Participants had a mean age of 22.7, with a range from 17 to 53 . The median age of participants was 19.0. Twenty-four participants did not report their age.

\section{Instruments}

The following measures were included in the battery:

The Levenson Self-Report Psychopathy Scale (LSRP). A 26-item scale constructed to examine the two factors found in the Hare Psychopathy Checklist-Revised, where participants are required to respond to a statement using a four-point Likert scale of disagree strongly, disagree somewhat, agree somewhat, and agree strongly. An example item from this scale is "I often admire a really clever scam". The two factors are Primary and Secondary Psychopathy (Levenson, Kiehl, \& Fitzpatrick, 1995).

Goldberg's International Personality Item Pool (IPIP). The IPIP is a widely accepted measure of the Five Factor Model. The IPIP test consists of 300 items providing Five Factor Model domain and facet scores. Items are endorsed on a four point Likert scale ranging from $\mathrm{F}$ "definitely false" to $\mathrm{T}$ "definitely true"/An example item is "I warm up quickly to others". The alpha reliability coefficients for the domains are reported on the IPIP website and range from .88 to .91 . The IPIP has been submitted to numerous reliability and validity examinations, all indicating its similarity to the NEO PI-R (Goldberg et al., 2006).

The Narcissism-Aloofness-Confidence-Empathy (NACE) scale. A 100-item four-point Likert scale ranging from $\mathrm{A}=$ definitely true to $\mathrm{D}=$ definitely false originally designed to discriminate among potential medical students, the NACE scale measures Narcissism, Aloofness, Confidence and Empathy. The 48 items in the Narcissism and Empathy subscales were used. 
An example item is "I am quite affectionate towards people". The validity of the four factor structure is supported by extensive replication, as is the Cronbach's alpha for all four scales, which has been found to range between .78 and .84 (Munro, Bore, \& Powis, 2005).

The MACH-IV. A 20-item scale designed to measure Machiavellian orientation; participants are required to respond using a 5-point Likert scale ranging from "strong disagreement" to "strong agreement" (Christie \& Geis, 1970). An example of an item from this scale is "It is wise to flatter important people". Research findings indicate weak to acceptable reliability and validity of the scale (Ray, 1982, 1983).

The Hogan Development Survey (HDS). ${ }^{1}$ The HDS is a commercially published and highly respected 154-item scale, used extensively in organisational psychology research to measure personality disorders. The survey is scored for eleven scales, each consisting of fourteen items (Furnham\& Crump, 2005; Hogan \& Hogan, 2001). The names of each scale are as follows: Excitable, Sceptical, Cautious, Reserved, Leisurely, Bold, Mischievous, Colourful, Imaginative, Diligent, and Dutiful. A description of each scale can be found in Table 1. Respondents are requested to "agree" or "disagree" with the items. The item data from this scale was not available to us for the calculation of reliability coefficients.

The Buss and Perry Aggression Questionnaire. A 29-item scale endorsed by participants on a seven-point Likert scale ranging from "extremely uncharacteristic of me" to "extremely characteristic of me". An example of an item from this scale is "I have threatened people I know". The internal consistency for the four scales ranged between .72 and .85 (Buss \& Perry, 1992). The scale consists of four factors labeled Physical Aggression, Verbal Aggression, Anger, and Hostility.

\section{Procedure}

Participants were tested in a group setting with a researcher present to administer the questionnaires. Participants were provided with a paper copy of the battery of tests and given two hours to complete them. Two versions of the questionnaire were designed. Version A had each measure in the following order: The IPIP, the MACH-IV, the Aggression Questionnaire, the LSRP, and the NACE. Half of the participants received version $A$ of the questionnaire, and the other half received version $\mathrm{B}$, which had the measures in reverse order to version $\mathrm{A}$, to account for potential fatigue effects. After each participant completed and returned their questionnaire, they were debriefed about the purpose of the study. The responses to all questionnaires except the HDS were hand entered into a spreadsheet for cleaning and scoring. The HDS response sheets were sent to the Australian agents who entered the data and provided a spreadsheet to us containing the eleven HDS scores for each participant.

\section{Results}

All data were examined for missing values that were replaced using the mid-point of the corresponding measure. Eight participants were excluded because they failed to complete one or more scales in the battery. Two hundred and thirty-three questionnaires were subsequently available for statistical analyses.

${ }^{1}$ The Hogan Development Survey was provided by the Australian Agents for Hogan Assessments, Peter Berry Consultancy.

\section{Descriptive Statistics}

The descriptive statistics for Psychopathy, Aggression, Machiavellianism, Narcissism and Empathy can be found in Table 2, including the alpha reliability for each scale. Participants who completed version A of the questionnaire were compared to those that completed version B to check for any order effects. No fatigue effects were detected for any of the scales in Table 2. Alpha coefficients indicated acceptable reliability for each of the scales. The sample mean for each scale was compared to the norm mean where available, and indicated that our sample was significantly different from the norm values for all scales except Primary Psychopathy, and Physical Aggression for males. Further inspection of the differences between the current study and the normative sample suggest a clinically important discrepancy for Machiavellianism, with our sample being substantially less Machiavellian.

Descriptive statistics for the Five Factor Model can be found in Table 3. No fatigue effects were detected for any of the Big Five domains. Alpha reliabilities for the domains were all found to be in the acceptable range.

Descriptive statistics for the Hogan Development Survey can be found in Table 4. No fatigue effects were detected for any of the eleven subscales. Table 4 presents norms for the HDS as percentiles, indicating how the present sample compares to the Australian norms for this measure. The $50^{\text {th }}$ percentile corresponds to the mean. As can be seen in Table 4, a substantial difference between the sample percentile score and the $50^{\text {th }}$ percentile exists for the first five scales of the HDS. The sample mean for Excitable, Sceptical, Cautious, Reserved and Leisurely scales is, in each instance, substantially higher.

\section{Table 2.}

Descriptive statistics for psychopathy, aggression, machiavellianism, narcissism and empathy.

\begin{tabular}{lcccc}
\hline & Mean & SD & Alpha & Norm Mean \\
\hline LSRP-Primary P & 29.95 & 7.42 & .86 & 29.13 \\
LSRP-Secondary P & $20.88^{* *}$ & 4.33 & .70 & 19.32 \\
Total Psychopathy & $50.84^{* *}$ & 9.99 & .86 & 48.45 \\
MACH-IV & $52.42^{* *}$ & 8.55 & .73 & 68.73 \\
NACE-Narcissism & $57.24^{* *}$ & 9.53 & .86 & 53.00 \\
NACE-Empathy & $71.56^{* *}$ & 8.20 & .84 & 74.00 \\
Aggression & 85.79 & 28.41 & .93 & $\mathrm{n} / \mathrm{a}$ \\
\hline
\end{tabular}

Notes: ${ }^{* *} p<.01$ sample mean compared to norm, LSRP-Primary $\mathrm{P}=$ Levenson Self-Report Primary Psychopathy' LSRP-Secondary P = Levenson Self-Report Secondary Psychopathy; MACH-IV = Machiavellianism Four Scale; NACENarcissism $=$ the Narcissism subscale of the Narcissism-Aloofness-ConfidenceEmpathy scale; NACE-Empathy = the Empathy subscale of the NarcissismAloofness-Confidence-Empathy scale.

Table 3.

Descriptive statistics for the five-factor model.

\begin{tabular}{lccc}
\hline & Mean & SD & Alpha \\
\hline Neuroticism (N) & 145.61 & 26.52 & .96 \\
Extraversion (E) & 168.30 & 19.35 & .93 \\
Openness (O) & 173.79 & 16.45 & .89 \\
Agreeableness (A) & 176.35 & 17.71 & .92 \\
Conscientiousness (C) & 169.15 & 18.79 & .92 \\
\hline
\end{tabular}


Table 4.

Descriptive statistics for hogan development survey.

\begin{tabular}{lccc}
\hline & Mean & SD & Percentile Norm \\
\hline Excitable & 6.15 & 3.49 & $83.80^{*}$ \\
Sceptical & 6.84 & 2.63 & $82.03^{*}$ \\
Cautious & 6.35 & 3.14 & $81.22^{*}$ \\
Reserved & 5.24 & 2.39 & $73.66^{*}$ \\
Leisurely & 6.59 & 2.23 & $78.28^{*}$ \\
Bold & 6.83 & 2.86 & 49.11 \\
Mischievous & 6.42 & 2.53 & $56.61^{*}$ \\
Colourful & 7.04 & 2.92 & $45.44^{*}$ \\
Imaginative & 6.87 & 2.79 & $64.77^{*}$ \\
Diligent & 9.30 & 2.99 & $55.06^{*}$ \\
Dutiful & 8.67 & 2.47 & $65.97^{*}$ \\
\hline
\end{tabular}

Note: ${ }^{*} p<.05$.

\section{Confirmatory Factor Analysis}

As all participants in the current sample had completed the LSRP scale, 241 cases were included in the confirmatory factor analyses. Inspection of skewness and kurtosis values on the item-level data indicated approximately normal distributions, thereby upholding the CFA assumption of normality. Even though missing data was replaced before statistical analysis was conducted using the midpoint of each scale, it was more appropriate to use the expectation-maximisation (EM) algorithm reported by Dempster, Laird, and Rubin (1977) for confirmatory factor analysis. Missing value analysis indicated that EM estimation was appropriate for replacing the missing data, $\chi^{2}(175)$ $=203.688, p<.05$ (Little, 1988). Confirmatory factor analysis with maximum likelihood estimation was then conducted using AMOS 18.0.

In the first analysis, the two factors were allowed to correlate and the model was estimated without any correlated errors. This initial model provided a reasonable fit of the data, $\chi^{2}(298)=$ 577.702 , with a normed chi-square $\left(\chi^{2} / \mathrm{df}\right)$ of 1.939 , a comparative fit index (CFI) of .80, and a root mean square error of approximation (RMSEA) of 0.06 . Inspection of the standardised residual covariance matrix and the modification indices suggested modifying the model to include correlated errors. However, as there was no theoretical justification for these changes, the approach used by Lynam, Whiteside and Jones (1999) was used, in which they added 17 measurement error correlations to the model. Adding these parameters did not significantly improve the fit of the model, $\chi^{2}(281)=557.944$, chi-square $\left(\chi^{2} / \mathrm{df}\right)$ of $1.986, \mathrm{CFI}=.80, \mathrm{RMSEA}=0.06$. The regression weights for the initial estimated model ranged from .19 to .66 , with the error variances ranging from .29 to .79 .

\section{Correlations}

The correlation between Primary and Secondary Psychopathy was .40. The correlations between Primary and Secondary Psychopathy and their theoretically related constructs can be found in Table 5, along with the absolute difference between correlations, and the t-value for the significance of these differences. The personality variables that significantly distinguished between the two factors were Aggression, Neuroticism,
Table 5.

Correlations between theoretically related constructs, primary, and secondary psychopathy scores.

\begin{tabular}{|c|c|c|c|c|}
\hline & $\begin{array}{c}\text { Psyc } \\
\text { Prime }\end{array}$ & $\begin{array}{c}\text { Psyc } \\
\text { Second }\end{array}$ & Difference & $t(d f=230)$ \\
\hline Neuroticism & -.01 & $.54^{* *}$ & .55 & $-9.40^{* * *}$ \\
\hline Conscientiousness & $-.27^{* *}$ & $-.69^{* *}$ & .42 & $7.82^{* * *}$ \\
\hline Excitable & $.13^{*}$ & $.51^{* *}$ & .38 & $-6.09^{* * *}$ \\
\hline Narcissism & $.71^{* *}$ & $.36^{* *}$ & .35 & $6.68^{* * *}$ \\
\hline Extraversion & .10 & $-.20^{* *}$ & .30 & $4.43^{* * *}$ \\
\hline Cautious & -.06 & $.24^{* *}$ & .30 & $-4.34^{* * *}$ \\
\hline Empathy & $-.44^{* *}$ & $-.17^{* *}$ & .27 & $-4.13^{* * *}$ \\
\hline Bold & $.31^{* *}$ & .05 & .26 & $3.79^{* * *}$ \\
\hline Total Aggression & $.36^{* *}$ & $.59^{* *}$ & .23 & $-3.91^{* * *}$ \\
\hline Agreeableness & $-.68^{* *}$ & $-.48^{* *}$ & .20 & $-3.81^{* * *}$ \\
\hline Colourful & $.25^{* *}$ & .05 & .20 & $2.86^{* *}$ \\
\hline Openness & $-.29^{* *}$ & $-.17^{* *}$ & .12 & -1.73 \\
\hline Mischievous & $.35^{* *}$ & $.24^{* *}$ & .11 & 1.63 \\
\hline Reserved & .11 & $.21^{* *}$ & .10 & -1.41 \\
\hline Leisurely & .10 & $.20^{* *}$ & .10 & -1.41 \\
\hline Imaginative & .06 & $.15^{*}$ & .09 & -1.26 \\
\hline Diligent & $-.21^{* *}$ & $-.30^{* *}$ & .09 & 1.31 \\
\hline Sceptical & $.22^{* *}$ & $.27^{* *}$ & .05 & -0.72 \\
\hline Dutiful & -.07 & -.11 & .04 & 0.56 \\
\hline Machiavellianism & $.63^{* *}$ & $.61^{* *}$ & .02 & 0.39 \\
\hline
\end{tabular}

Notes: ${ }^{*} p<.05 ;{ }^{* *} p<.01 ;{ }^{* * *} p<.001$.

Conscientiousness, Agreeableness, HDS Excitable, HDS Bold, Narcissism, and Empathy. In particular, Primary Psychopathy was strongly and positively related to Narcissism, Empathy, and the HDS Bold scale, corresponding to Antisocial personality traits. Secondary Psychopathy was positively related to Neuroticism and HDS Excitable (Borderline), and negatively to Conscientiousness.

\section{Discussion}

Examination of the results indicated strong support for the study hypotheses. Confirmatory factor analysis indicated that the two-factor model provided a reasonable fit to the data, thereby supporting the two-component structure of Psychopathy. The fit indices obtained in the current research were comparable to those of Brinkley, Schmitt, Smith, and Newman (2001) and Lynam, Whiteside and Jones (1999), however both concluded poor fit based on these results. Both previous studies introduced seventeen correlated error terms to their respective models, which improved the fit indices only in the case of Lynam et al. Despite the improvement in fit, there does not appear to be a theoretical basis for expecting these correlated error terms, which also impede the interpretation of the model. However, given that the normed chi-square was 1.939 in the present study, it can be concluded that there is support for the two-factor structure of the LSRP.

Examination of the correlations with other personality variables likewise provided support for the construct validity of the 
two-component structure. As expected, both Primary and Secondary Psychopathy was negatively related to Agreeableness and Empathy, and positively with Aggression, Narcissism, and the Mischievous HDS subscale, corresponding to Antisocial personality traits (Hogan \& Hogan, 2001). However, t-tests for the difference between dependent sample correlations indicated that all but Mischievous had significantly different relationships with the two factors. For example, Narcissism was positively correlated with both factors, but there was a difference in the magnitude of these correlations of .35, with Primary Psychopathy having a correlation with Narcissism of .71.

As expected, Primary Psychopathy was also related to the Bold and Colourful HDS scales, corresponding to Narcissistic and Histrionic traits (Hogan \& Hogan, 2001). Secondary Psychopathy was not related to these scales. The comparatively stronger correlations with Narcissism and Empathy indicate that Primary Psychopathy can be defined by a sense of entitlement and attention seeking behaviours, coupled with a lack of consideration for the feelings of others. On the other hand, Secondary Psychopathy was negatively related to Conscientiousness, as well as positively related to Neuroticism, and to the Excitable and Sceptical HDS scales corresponding to Borderline and Paranoid personality traits (Hart \& Hare, 1996; Lynam, Whiteside, \& Jones, 1999). This indicates that Secondary Psychopathy may be characterised by impulsivity and emotional reactivity, including increased levels of paranoia. However, Primary Psychopathy was also related to Sceptical, and there was no significant difference between the correlations, indicating that Paranoid personality traits may be common to both constructs.

Contrary to expectations, Machiavellianism was related to both Primary and Secondary Psychopathy, with no significant difference between the correlations. This fails to replicate the results obtained by Wastell and Booth (2003). It is possible that Machiavellianism is a construct that is related to both components of Psychopathy, as was suggested by Lee and Ashton (2005). An alternative explanation could be the lower levels of Machiavellianism evident in the current sample in comparison to the normative sample. More investigation may be needed to determine the reason for the observed relationships.

Several limitations of the current study require mentioning. As previously discussed, Machiavellianism levels are significantly lower than the norms in the current sample, which may have impacted on our ability to differentiate between Primary and Secondary Psychopathy. A likely explanation for the lower Machiavellianism levels is the proportion of women in the current sample. Evidence indicates that both Machiavellianism and Psychopathy levels are lower in females (Christie \& Geis, 1970; Williams, Paulhus, \& Hare, 2007), though the average Psychopathy scores were not significantly different from norms in this case, making the gender proportion explanation unlikely for Machiavellianism.

Another limitation of the current study involves the fact that the current sample scored substantially higher than the Australian norm on the Excitable, Sceptical, Cautious, Reserved and Leisurely scales. An improbable explanation for these findings could be that the student sample had high levels of Borderline, Paranoid, Avoidant, Schizoid, and Passive-Aggressive traits. It is more likely that the HDS scale did not operate exactly as expected. Unfortunately the item-level data were not made available for comparison. Given that the majority of study participants were undergraduate psychology students, it is possible that the normative group of Australian managers was not an appropriate comparison population. The homogeneity of the sample may have also introduced a restriction of range issue. Although our hypotheses were supported, further research is required to clarify these issues.

The two-component model of Psychopathy may have application in forensic and clinical samples. The two-factor model has been derived from the "gold standard" psychopathy diagnostic tool, the Psychopathy Checklist Revised (PCL-R; Hare, 1985). Given the current results, which suggest a different personality profile for each construct, it is likely that this would also translate into behaviour, but further research is necessary to validate the model.

In conclusion, the findings of the current study appear to support Karpman's (1948) two factor structure of Psychopathy, as well as the validity of the structure contained within the Levenson Self-Report Psychopathy Scale (Levenson, Kiehl, \& Fitzpatrick, 1995). Preliminary evidence for the construct validity of Primary and Secondary Psychopathy has been obtained. It appears increasingly likely that there are two types of Psychopathy, one that taps into callous, manipulative and selfish interpersonal attitudes, and the other that reflects impulsivity and emotional instability.

\section{Acknowledgements}

Thanks go to Peter Berry Consultancy, who provided the Hogan Development Survey for use in this study. The assistance of Mrs. Paula Bridge in the data collection process is also recognised.

\section{REFERENCES}

Andrew, J., Cooke, M., \&Muncer, S. (2008). The relationship between empathy and Machiavellianism: An alternative to empathizing-systemizing theory. Personality and Individual Differences, 44, 12031211. doi:10.1016/j.paid.2007.11.014

Blackburn, R., \& Coid, J. W. (1998). Psychopathy and the dimensions of personality disorder in violent offenders.Personality and Individual Differences, 25, 129-145. doi:10.1016/S0191-8869(98)00027-0

Brinkley, C. A., Schmitt, W. A., Smith, S. S., \& Newman, J. P. (2001). Construct validation of a self-report psychopathy scale: Does Levenson's self-report psychopathy scale measure the same constructs as Hare's psychopathy checklist-revised? Personality and Individual Differences, 31, 1021-1038. doi:10.1016/S0191-8869(00)00178-1

Buss, A. H., \& Perry, M. (1992). The Aggression Questionnaire. Journal of Personality and Social Psychology, 63, 452-459. doi: $10.1037 / 0022-3514.63 .3 .452$

Christie, R., \& Geis, F. L. (1970). Studies in Machiavellianism. New York: Academic Press.

Cleckley, H. (1950). The mask of sanity: An attempt to clarify some issues about the so-called psychopathic personality. Oxford, England: Mosby.

Decuyper, A. P., De Fruyt, F., \& Buschman, J. (2008). A five-factor model perspective on psychopathy and comorbid Axis-II disorders in a forensic-psychiatric sample. International Journal of Law and Psychiatry, 31, 394-406. doi:10.1016/j.ijlp.2008.08.008

Dempster, A. P., Laird, N. M., \& Rubin, D. B. (1977). Maximum likelihood from incomplete data via the EM algorithm. Journal of the Royal Statistical Society. Series B (Methodological), 39, 1-38.

Flores-Mendoza, C. E., Alvarenga, M. A. S., Herrero, O., \& Abad, F. J. (2008). Factor structure and behavioural correlates of the psychopathy checklist-revised. Personality and Individual Differences, 45, 584-590. doi:10.1016/j.paid.2008.06.016

Forth, A. E., Brown, S. L., Hart, S. D., \& Hare, R. D. (1996). The assessment of psychopathy in male and female noncriminals: Reliabil- 
ity and validity. Personality and Individual Differences, 20, 531-543. doi:10.1016/0191-8869(95)00221-9

Freidenfelt, J., \& Klinteberg, B. (2007). Exploring adult personality and psychopathy tendencies in former childhood hyperactive delinquent males. Journal of Individual Differences, 28, 27-36. doi:10.1027/1614-0001.28.1.27

Furnham, A., \& Crump, J. (2005). Personality traits, types, and disorders: An examination of the relationship between three self-report measures. European Journal of Personality, 19, 167-184. doi: $10.1002 /$ per. 543

Goldberg, L. R., Johnson, J. A., Eber, H. W., Hogan, R., Ashton, M. C., Cloniger, C. R., \& Gough, H. C. (2006). The international personality item pool and the future of public-domain personality measures. Journal of Research in Personality, 40, 84-96.

doi:10.1016/j.jrp.2005.08.007

Hare, R. D. (1985). Comparison of procedures for the assessment of psychopathy. Journal of Consulting and Clinical Psychology, 53, 7-16. doi:10.1037/0022-006X.53.1.7

Hart, S. D., \& Hare, R. D. (1989). Discriminant validity of the psychopathy checklist in a forensic psychiatric population. Psychological Assessment, 1, 211-218. doi:10.1037/1040-3590.1.3.211

Hart, S. D., \& Hare, R. D. (1996). Psychopathy and antisocial personality disorder.Current Opinion in Psychiatry, 9, 129-132. doi:10.1097/00001504-199603000-00007

Hildebrand, M., \& de Ruiter, C. (2004). PCL-R psychopathy and its relation to DSM-IV Axis I and II disorders in a sample of male forensic psychiatric patients in the Netherlands. International Journal of Law and Psychiatry, 27, 233-248. doi:10.1016/j.ijlp.2004.03.005

Hogan, R., \& Hogan, J. (2001). Assessing leadership: A view from the dark side. International Journal of Selection and Assessment, 9, 40. doi:10.1111/1468-2389.00162

Jakobwitz, S., \& Egan, V. (2006). The dark triad and normal personality traits. Personality and Individual Differences, 40, 331-339. doi:10.1016/j.paid.2005.07.006

Karpman, B. (1948). The myth of the psychopathic personality. American Journal of Psychiatry, 104, 523-534. doi:10.1176/appi.ajp.104.9.523

Lee, K., \& Ashton, M. C. (2005). Psychopathy, machiavellianism, and narcissism in the five-factor model and the HEXACO model of personality structure. Personality and Individual Differences, 38, 15711582. doi:10.1016/j.paid.2004.09.016

Lee, Z., \&Salekin, R.T. (2010). Psychopathy in a noninstitutional sample: Differences in primary and secondary subtypes. Personality Disorders: Theory, Research, and Treatment, 1, 153-169. doi: 10.1037/a0019269

Levenson, M. R., Kiehl, K. A., \& Fitzpatrick, C. M. (1995). Assessing psychopathic attributes in a noninstitutionalized population. Journal of Personality and Social Psychology, 68, 151-158. doi:10.1037/0022-3514.68.1.151

Lilienfeld, S. O., \& Andrews, B. P. (1996). Development and prelimi- nary validation of a self-report measure of psychopathic personality traits in noncriminal populations. Journal of Personality Assessment, 66, 488-524. doi:10.1207/s15327752jpa6603_3

Little, R. J. A. (1988).A test of missing completely at random for multivariate data with missing values. Journal of the American Statistical Association, 83, 1198-1202. doi:10.2307/2290157

Lynam, D. R. (2002). Psychopathy from the perspective of the fivefactor model of personality. In P. T. Costa Jr. \& T. A. Widiger (Eds.), Personality disorders and the five-factor model of personality (2nd ed., pp. 325-348). Washington, DC: American Psychological Association. doi: $10.1037 / 10423-020$

Lynam, D. R., \& Derefinko, K. J. (2006). Psychopathy and personality. In C. J. Patrick (Ed.), Handbook of psychopathy (pp. 133-155). New York: Guilford Press.

Lynam, D. R., Whiteside, S., \& Jones, S. (1999). Self-reported psychopathy: A validation study. Journal of Personality Assessment, 73, 110-132. doi:10.1207/S15327752JPA730108

Munro, D., Bore, M., \& Powis, D. (2005). Personality factors in professional ethical behaviour: Studies of empathy and narcissism. Australian Journal of Psychology, 57, 49-60. doi: $10.1080 / 00049530412331283453$

Paulhus, D. L., \& Williams, K. M. (2002). The dark triad of personality: Narcissism, machiavellianism and psychopathy. Journal of Research in Personality, 36, 556-563. doi:10.1016/S0092-6566(02)00505-6

Ray, J. J. (1982). Machiavellianism, forced-choice formats and the validity of the F scale: A rejoinder to Bloom. Journal of Clinical Psychology, 38, 779-782.

doi:10.1002/1097-4679(198210)38:4<779::AID-JCLP2270380414> $3.0 . \mathrm{CO} ; 2-\mathrm{N}$

Ray, J. J. (1983). Defective validity of the machiavellianism scale. The Journal of Social Psychology, 119, 291-292. doi: $10.1080 / 00224545.1983 .9922836$

Ross, S. R., Bye, K., Wrobel, T .A., \& Horton, R. S. (2008). Primary and secondary psychopathic characteristics and the schedule for nonadaptive and adaptive personality (SNAP). Personality and Individual Differences, 45, 249-254. doi:10.1016/j.paid.2008.04.007

Templeman, R., \& Wong, S. (1994). Determining the factor structure of the psychopathy checklist: A converging approach. Multivariate Experimental Clinical Research, 10, 157-166.

Vitacco, M. J., Neumann, C. S., \& Jackson, R. L. (2005). Testing a four-factor model of psychopathy and its association with ethnicity, gender, intelligence, and violence. Journal of Consulting and Clinical Psychology, 73, 466-476. doi:10.1037/0022-006X.73.3.466

Wastell, C., \& Booth, A. (2003). Machiavellianism: An alexithymic perspective. Journal of Social and Clinical Psychology, 22, 730-744. doi:10.1521/jscp.22.6.730.22931

Williams, K. M., Paulhus, D. L., \& Hare, R. D. (2007). Capturing the four-factor structure of psychopathy in college students via self-report. Journal of Personality Assessment, 88, 205-219. doi:10.1080/00223890701268074 